\title{
Synovial cysts of the spine: long-term follow-up after surgical treatment of 141 cases in a single-center series and comprehensive literature review of 2900 degenerative spinal cysts
}

\author{
Markus Bruder, MD, Adriano Cattani, MD, PhD, Florian Gessler, MD, Christian Droste, MD, \\ Matthias Setzer, MD, PhD, Volker Seifert, MD, PhD, and Gerhard Marquardt, MD, PhD \\ Department of Neurosurgery, Goethe University, Frankfurt, Germany
}

OBJECTIVE Synovial cysts of the spine are rare lesions, predominantly arising in the lumbar region. Despite their generally benign behavior, they can cause severe symptoms due to compression of neural structures in the spinal canal. Treatment strategies are still a matter of discussion. The authors performed a single-center survey and literature search focusing on long-term results after minimally invasive surgery.

METHODS A total of 141 consecutive patients treated for synovial cysts of the lumbar spine between 1997 and 2014 in the authors' department were analyzed. Medical reports with regard to signs and symptoms, operative findings, complications, and short-term outcome were reviewed. Assessment of long-term outcome was performed with a standardized telephone questionnaire based on the Oswestry Disability Index (ODI). Furthermore, patients were questioned about persisting pain, symptoms, and further operative procedures, if any. Subjective satisfaction was classified as excellent, good, fair, or poor based on the Macnab classification.

RESULTS The approach most often used for synovial cyst treatment was partial hemilaminectomy in $70 \%$; hemilaminectomy was necessary in $27 \%$. At short-term follow-up, the presence of severe and moderate leg pain had decreased from $93 \%$ to $5 \%$. The presence of low-back pain decreased from $90 \%$ to $5 \%$. Rates of motor and sensory deficits were reduced from $40 \%$ to $14 \%$ and from $45 \%$ to $6 \%$, respectively. The follow-up rate was $58 \%$, and the mean follow-up period was 9.3 years. Both leg pain and low-back pain were still absent in $78 \%$. Outcome based on the Macnab classification was excellent in $80 \%$, good in $14 \%$, fair in $1 \%$, and poor in $5 \%$. According to the ODI, $78 \%$ of patients had no or only minimal disability, $16 \%$ had moderate disability, and $6 \%$ had severe disability at the time of follow-up. In this cohort, $7 \%$ needed surgery due to cyst recurrence, and $9 \%$ required a delayed stabilization procedure after the initial operation.

CONCLUSIONS Surgical treatment with resection of the cyst provides favorable results in outcome. Excellent or good outcome persisting for a long-term follow-up period can be achieved in the vast majority of cases. Complication rates are low despite an increased risk of dural injury. With facet-sparing techniques, the stability of the segment can be preserved, and resection of spinal synovial cysts does not necessarily require segmental fusion.

https://thejns.org/doi/abs/10.3171/2016.12.SPINE16756

KEY WORDS synovial cyst; ganglion cyst; pseudocyst; juxtafacet cyst; radiculopathy; spine; lumbar

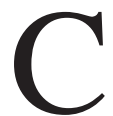
YSTIC joint-adjacent lesions are a known problem of degeneration and were first described by Baker in $1877 . .^{10}$ These cysts can occur on every joint in the body and cause neurological deficits in cases of nerve compression. However, nerve root compression is the lead- ing symptom in the rare event of cysts adjacent to joints of the spinal column, as first described by Vossschulte and Börger in $1950 .^{96}$

Pathogenesis of those cysts is still a matter of discussion, but degeneration and destabilization seem to be the

ABBREVIATIONS ODI = Oswestry Disability Index. 
underlying pathology in current models of cyst formation..$^{23,34,101}$ Many treatment options, such as conservative management, corticosteroid injection, percutaneous cyst rupture, or aspiration and surgical excision with or without fusion have been described. Because conservative and percutaneous therapies do not provide durable effects, ${ }^{20,64}$, 75,87 resection of the cyst and decompression of the neural structures is the therapy of choice and can facilitate immediate and long-lasting improvement of the symptoms. Lack of stability is often suspected to play a major part in cyst development, but the role of fusion combined with cyst resection procedures is still unclear. Therefore, we performed this retrospective survey focusing on longterm effects after cyst resection without concomitant fusion.

\section{Methods}

The clinical data for all 141 patients who underwent operations to treat juxtafacet cysts of the spine at our institution between January 1997 and January 2014 were retrospectively obtained by reviewing medical reports and outpatient charts. There were 51 men $(36.2 \%)$ and 90 women $(63.8 \%$ ), with a mean age of 65.2 years (range 1885 years). The records of each patient were analyzed with respect to clinical signs and symptoms, intraoperative findings, surgery-related complications, short-term outcome (6 weeks), and further outpatient care. To assess the long-term results, standardized telephone interviews were performed. For this purpose, a structured questionnaire was designed to obtain precise indications about each patient's potential residual symptoms and additional surgical procedures. To record the possible presence of back pain and/or sciatica, the patients were queried about pain by using the verbal rating scale $(0=$ no pain, $10=$ maximum pain). Furthermore, the patients were asked about persisting sensory and/or motor disturbances, if any. Other information concerned physical capacity, potential restrictions in activities of daily living, and resumption of work. Questions related thereto were based on the Oswestry Disability Index (ODI). ${ }^{57}$ Subjective satisfaction with the result of surgery was classified as excellent (no pain), good (some pain), fair (moderate pain), and poor (unchanged or worse), based on the Macnab classification..$^{54}$ This study was approved by the local ethics committee.

\section{Surgical Procedure}

For decompression of neural structures and resection of the cysts, a facet-sparing approach was used. All procedures were performed with the aid of an operating microscope. After a medial skin incision, the thoracolumbar fascia was opened in a paramedian fashion, and the autochthonous muscles were subfascially dissected from the laminae. In $69.8 \%$ of the patients a partial hemilaminectomy was done, and in $26.4 \%$ a hemilaminectomy was performed. A complete laminectomy was necessary in only $1.6 \%$, and interlaminary fenestration was sufficient for cyst resection in $2.3 \%$. In a majority of cases $(63.5 \%)$, no resection of the facet was necessary. The medial one-third of the facet joint was resected in $7 \%$, and two-thirds was resected in $29.5 \%$ of the patients. After visualization of the cyst's margins, careful cyst resection was performed. None of the patients received any kind of fusion or stabilization in the initial procedure.

\section{Literature Review}

We performed an extensive literature search using PubMed and the following terms: "lumbar synovial cyst," "thoracic synovial cyst," "cervical synovial cyst," "spinal synovial cyst," "juxtafacet cyst," "ganglion cyst [and] spine," and "cyst [and] spine" on May 1, 2016. Overall, 305 publications pertaining to degenerative spinal cysts were reviewed and included in the literature review analysis. We found 182 case reports, 70 reports of 2-10 cases, 43 reports including $11-50$ cases, 4 reports with 51-100 cases, and 6 reports with more than 100 cases matching our search parameters.

\section{Statistical Analyses}

Statistical analyses were performed using Student's ttest, the chi-square test, or Fisher's exact test as indicated. Results with a $\mathrm{p}$ value $<0.05$ were considered statistically significant. Statistical analyses and calculations were made using standard commercial software (IBM SPSS Statistics, version 22).

\section{Results \\ Preoperative Findings}

The juxtafacet cysts were located at the level of L1/2 in 2 patients (1.4\%); L2/3 in 3 (2.1\%); L3/4 in 29 (20.6\%); $\mathrm{L} 4 / 5$ in 87 (61.7\%); and at the L5/S1 level in $19(13.5 \%)$ patients (Table 1). The cyst was located on the left side in 70 patients $(49.6 \%)$ and on the right side in $68(48.2 \%)$. In 3 patients (2.1\%), cysts were located on both sides. In 1 patient, the cyst was located at the left C7/T1 facet joint $(0.7 \%)$. The mean duration of symptoms was $6.4 \pm 5.6$ months (mean \pm SD). On admission, 131 patients $(92.9 \%)$ suffered from leg pain, either of the femoral or sciatic type, and 127 of the patients $(90.1 \%)$ reported low-back pain. As many as $45.4 \%$ of the patients $(n=64)$ had sensory deficits, and in $40.4 \%(\mathrm{n}=57)$ paresis of the reference muscles of the affected spinal nerve root was present. Bladder and/or bowel disorders were present in 7 patients (5\%) (Table 2).

\section{Radiological Findings}

Diagnosis was verified with MRI scans in 129 patients $(91.5 \%)$, and 20 cases $(14.2 \%)$ had only or additional CT scans. In 2 patients $(1.4 \%)$, the diagnosis was verified with myelography due to inconclusive CT scans and contraindication for MRI.

Stenosis of the spinal canal was present in 83 cases (58.9\%), and $76.3 \%$ had additional degenerative findings of the spine. Spondylolisthesis was present in $23.4 \%$ of cases. The degree of listhesis was most often only minor (Meyerding Grade I; $19.9 \%$ of all cases).

\section{Intraoperative Findings}

In $71.6 \%$ of cases $(n=101)$, the cyst showed strong adherence to the dura mater. However, complete resection 
TABLE 1. Location of synovial cysts of the spinal column

\begin{tabular}{|c|c|c|c|c|c|c|c|c|}
\hline \multirow[b]{3}{*}{ Location } & \multicolumn{4}{|c|}{ Present Series } & \multirow{2}{*}{\multicolumn{2}{|c|}{ Literature* $^{*}$}} & \multirow{2}{*}{\multicolumn{2}{|c|}{ Total }} \\
\hline & \multicolumn{2}{|c|}{ Total } & \multicolumn{2}{|c|}{ Long-Term FU } & & & & \\
\hline & $n=141$ & $\%$ & $\mathrm{n}=81$ & $\%$ & $n=2900$ & $\%$ & $n=3041$ & $\%$ \\
\hline Cervical & 1 & 0.7 & 1 & 1.2 & 192 & 6.6 & 193 & 6.3 \\
\hline $\mathrm{Oc} / \mathrm{C} 1$ & - & - & - & - & 12 & 0.5 & 12 & 0.4 \\
\hline $\mathrm{C} 1 / 2$ & - & - & - & - & 32 & 1.3 & 32 & 1.1 \\
\hline $\mathrm{C} 2 / 3$ & - & - & - & - & 6 & 0.2 & 6 & 0.2 \\
\hline $\mathrm{C} 3 / 4$ & - & - & - & - & 20 & 0.8 & 20 & 0.7 \\
\hline $\mathrm{C} 4 / 5$ & - & - & - & - & 22 & 0.9 & 22 & 0.7 \\
\hline $\mathrm{C} 5 / 6$ & - & - & - & - & 7 & 0.3 & 7 & 0.2 \\
\hline C6/7 & - & - & - & - & 12 & 0.5 & 12 & 0.4 \\
\hline $\mathrm{C} 7 / \mathrm{T} 1$ & 1 & 0.7 & 1 & 1.2 & 81 & 2.8 & 82 & 2.7 \\
\hline Thoracic & - & - & - & - & 50 & 1.7 & 50 & 1.6 \\
\hline $\mathrm{T} 1 / 2$ & - & - & - & - & 2 & 0.1 & 2 & 0.1 \\
\hline $\mathrm{T} 2 / 3$ & - & - & - & - & 1 & 0.03 & 1 & 0.03 \\
\hline $\mathrm{T} 3 / 4$ & - & - & - & - & - & - & - & - \\
\hline $\mathrm{T} 4 / 5$ & - & - & - & - & 2 & 0.1 & 2 & 0.1 \\
\hline $\mathrm{T} 5 / 6$ & - & - & - & - & - & - & - & - \\
\hline T6/7 & - & - & - & - & - & - & - & - \\
\hline $\mathrm{T} 7 / 8$ & - & - & - & - & 2 & 0.1 & 2 & 0.1 \\
\hline $\mathrm{T} 8 / 9$ & - & - & - & - & 1 & 0.03 & 1 & 0.03 \\
\hline $\mathrm{T} 9 / 10$ & - & - & - & - & 6 & 0.2 & 6 & 0.2 \\
\hline $\mathrm{T} 10 / 11$ & - & - & - & - & 6 & 0.2 & 6 & 0.2 \\
\hline $\mathrm{T} 11 / 12$ & - & - & - & - & 13 & 0.5 & 13 & 0.4 \\
\hline T12/L1 & - & - & - & - & 16 & 0.6 & 16 & 0.5 \\
\hline Lumbar & 140 & 99.3 & 80 & 98.8 & 2658 & 91.7 & 2798 & 92.0 \\
\hline $\mathrm{L} 1 / 2$ & 2 & 1.4 & 2 & 2.5 & 13 & 0.5 & 15 & 0.6 \\
\hline $\mathrm{L} 2 / 3$ & 3 & 2.1 & 2 & 2.5 & 69 & 2.8 & 72 & 2.8 \\
\hline$L 3 / 4$ & 29 & 20.6 & 16 & 19.8 & 336 & 13.7 & 365 & 14.1 \\
\hline L4/5 & 87 & 61.7 & 47 & 58.0 & 1429 & 58.2 & 1516 & 58.4 \\
\hline L5/S1 & 19 & 13.5 & 13 & 16.0 & 349 & 14.2 & 368 & 14.2 \\
\hline L5/L6 & - & - & - & - & 3 & 0.1 & 3 & 0.1 \\
\hline
\end{tabular}

of the cyst was achieved in $94.3 \%(n=133)$. In 12 cases $(8.5 \%)$ a dural tear was seen, and a leakage of CSF was present in 7 of these cases $(5.0 \%)$, necessitating reconstruction of the dural layer.

\section{Postoperative Findings}

Short-term follow-up revealed that 115 (87.8\%) of those 131 patients reporting leg pain before surgery were completely pain free after surgery, whereas 16 patients $(12.2 \%)$ reported that some leg pain persisted. Thus, the incidence of major and moderate leg pain decreased from $92.9 \%$ to $5.3 \%$. Low-back pain similarly declined from $90.1 \%$ to $4.7 \%$; 109 of 127 patients $(85.8 \%)$ with preoperative low-back pain were pain free after surgery, and another $12(9.4 \%)$ reported significant reduction. Sensory deficits were no longer present in 55 of 64 patients $(85.9 \%)$ with preoperative sensory deficits. Motor deficits, on the other hand, did not disappear to such an extent: 36 of 57 patients $(63.2 \%)$ with preoperative paresis showed no reduction in muscle strength postoperatively, $13(22.8 \%)$ showed amelioration, and the remaining $8(14.0 \%)$ were unchanged.

Postoperative complications were observed in 11 patients $(7.8 \%)$ and are presented in Table 3 . One patient $(0.7 \%)$ developed a hematoma in the wound area; he was treated conservatively and made an uneventful recovery. Two patients (1.4\%) developed a wound healing disorder (1 that could be treated conservatively, and 1 that required surgical revision), and the subsequent course was uneventful in both. Another 2 patients $(1.4 \%)$ presented with acute postoperative worsening of symptoms due to epidural hematoma. Both patients recovered fully after surgical 
TABLE 2. Characteristics, symptoms, and preoperative findings in patients with cysts of the spinal column

\begin{tabular}{|c|c|c|c|c|}
\hline \multirow[b]{2}{*}{ Factor } & \multicolumn{2}{|c|}{ Present Series } & \multirow[b]{2}{*}{$\begin{array}{c}\text { Literature, } \\
n=2900\end{array}$} & \multirow[b]{2}{*}{$\begin{array}{c}\text { Total, } \\
\mathrm{n}=3041\end{array}$} \\
\hline & $\begin{array}{c}\text { Total, } \\
n=141\end{array}$ & $\begin{array}{l}\text { Long- } \\
\text { Term FU, } \\
n=81\end{array}$ & & \\
\hline \multicolumn{5}{|l|}{ Patient characteristics } \\
\hline Mean age in yrs & 65.2 & 65.0 & 62.6 & 62.8 \\
\hline Female & $64 \%$ & $68 \%$ & $56 \%$ & $56 \%$ \\
\hline \multicolumn{5}{|l|}{ Symptoms } \\
\hline Radiculopathy & $93 \%$ & $90 \%$ & $83 \%$ & $84 \%$ \\
\hline Neck or back pain & $90 \%$ & $91 \%$ & $63 \%$ & $65 \%$ \\
\hline Myelopathy* & $0 \%$ & $0 \%$ & $49 \%$ & $49 \%$ \\
\hline Sensory deficit & $45 \%$ & $47 \%$ & $40 \%$ & $40 \%$ \\
\hline Motor deficit & $40 \%$ & $36 \%$ & $32 \%$ & $32 \%$ \\
\hline $\begin{array}{l}\text { Neurogenic claudica- } \\
\text { tiont }\end{array}$ & $30 \%$ & $30 \%$ & $27 \%$ & $27 \%$ \\
\hline $\begin{array}{c}\text { Cauda equina syndrome } \\
\text { w/ or w/o bowel \&/or } \\
\text { bladder dysfunction } \ddagger\end{array}$ & $5 \%$ & $5 \%$ & $4 \%$ & $4 \%$ \\
\hline Bilat symptoms & $20 \%$ & $21 \%$ & $26 \%$ & $26 \%$ \\
\hline Trauma & $1 \%$ & $1 \%$ & $7 \%$ & $7 \%$ \\
\hline Spondylolisthesis & $23 \%$ & $24 \%$ & $31 \%$ & $31 \%$ \\
\hline
\end{tabular}

The numbers given in the footnotes do not reflect how often the symptom occurred, but how many patients were counted in the subgroup. For example, $49 \%$ of patients in the literature who had cervical or thoracic cysts had myelopathy, and so on.

* Only includes patients with cervical or thoracic cysts: $n=1$ in this series, $n=$ 242 in the literature, and $n=243$ overall.

† Only includes patients with lumbar cysts: $n=140$ in this series, $n=2658$ in the literature, and $n=2798$ overall.

$\ddagger$ Only includes patients with thoracic or lumbar cysts: $n=140$ in this series, $n$

$=2708$ in the literature, and $n=2848$ overall.

evacuation of the hematoma. One patient $(0.7 \%)$ developed deep vein thrombosis and was treated with low-molecular-weight heparin. There was no sign of pulmonary embolism. Six patients $(4.3 \%)$ had postoperative leakage of CSF. In 2 of those, a 3-day lumbar drain was sufficient, but 4 necessitated revision surgery.

Overall, 8 patients suffered from recurrent cysts (5.7\%) at the same level, and 7 of them needed reoperation due to aggravation of symptoms. Three of the recurrent cysts developed during the 1st postoperative year, 1 in the 2 nd, and 2 in the 3 rd postoperative year. Two more developed after 78 and 95 months, respectively.

Overall, 9 patients (6.4\%) required postoperative "delayed" fusion of the affected level due to spondylolisthesis. Two of these patients underwent a stabilization procedure in the 2 nd postoperative year, 1 in the 5 th, and 1 in the 8 th year. Four patients required fusion 9 years after, and 1 patient 14 years after cyst resection.

\section{Long-Term Follow-Up}

To conduct the patient survey for assessment of longterm results as comprehensively and completely as possible, an intensive search for the patients was conducted.
A total of 39 patients were lost to follow-up due to moving, whereas $102(72.3 \%)$ could be located. An interview, however, was not conducted in 21 patients: 17 had died already, 3 could not provide any information due to dementia that had emerged in the meantime, and 1 patient refused to participate in the survey. Thus, a total of $81 \mathrm{com}-$ plete telephone interviews accounting for a respondent rate of $57.4 \%$ were conducted. The mean follow-up was $111 \pm 44.3$ months (mean $\pm \mathrm{SD}$; range 17-213 months).

At the time of follow-up, 5 patients $(6.2 \%)$ reported back pain, whereas 18 patients $(22.2 \%)$ reported some back pain and leg pain exclusively under physical stress. Twelve patients $(14.8 \%)$ had sensory deficits and 8 patients $(9.9 \%)$ reported motor dysfunction at the time of follow-up.

In the long-term follow-up group, recurrent cysts were observed in $7.4 \%$, and 7 patients $(8.6 \%)$ required delayed fusion (Table 3). A detailed comparison of patients with and without delayed fusion is given in Table 4 . There were no differences in patient characteristics, cyst level, radiological findings, symptoms, or surgical techniques. Follow-up time was longer in patients who needed delayed fusion than in those who did not, but not on a significant level. However, an ODI-based evaluation at the time of follow-up revealed a significantly higher rate of disabilities in patients who had undergone delayed fusion during the follow-up period than in patients who had not. None of the patients was classified as "crippled" or "bed bound."

Overall, 15 patients (18.5\%) suffered from other diseases that affected their clinical condition at the time of the survey. Twelve patients (16\%) had rheumatoid or arthritic problems of the joints, $1(1.2 \%)$ had polyneuropathy, 1 $(1.2 \%)$ had both rheumatoid arthritis and polyneuropathy, and $1(1.2 \%)$ was diagnosed with encephalitis disseminata after the cyst operation was performed.

Nevertheless, despite residual symptoms, the vast majority of patients expressed satisfaction with the result of surgery. Based on the Macnab classification, the subjectively rated long-term results were as follows: $80.2 \%$ excellent (65 patients), $13.6 \%$ good (11 patients), 1.2\% fair (1 patient), and $4.9 \%$ poor (4 patients). Of the 81 patients, 37 (45.7\%) were gainfully employed before surgery, whereas the other patients were pensioners, housewives, or unemployed. After surgery, 36 patients (97.3\%) remained in their previous occupation, and 1 patient (2.7\%) applied for a certificate of disability.

\section{Discussion}

Cysts adjacent to joints are a common problem of degeneration and were first described by Baker in $1877 . .^{10}$ These cysts mostly involve the joints of the extremities, but can (rarely) be found in the spinal canal ${ }^{78}$ Even without a considerable degree of movement-apart from the atlantooccipital and atlantoaxial joint-physical stress can provoke a degenerative process of the facet joints, possibly leading to cystic formations causing pressure on neural structures. ${ }^{34,101}$

The incidence of cystic lesions in radiological studies ranges between $0.5 \%$ and $1.1 \%$ in older studies. However, due to better diagnostic possibilities with MRI, the 
TABLE 3. Surgically treated patients, complications, and postoperative course

\begin{tabular}{|c|c|c|c|c|c|c|c|c|}
\hline \multirow[b]{3}{*}{ Variable } & \multicolumn{4}{|c|}{ Present Series } & & & & \\
\hline & \multicolumn{2}{|c|}{ Total } & \multicolumn{2}{|c|}{ Long-Term FU } & \multicolumn{2}{|c|}{ Literature } & \multicolumn{2}{|c|}{ Total } \\
\hline & No. & $\%$ & No. & $\%$ & No.. & $\%$ & No. & $\%$ \\
\hline Surgical treatment & 141 & 100 & $81 / 141$ & 57.5 & 1721 & 100 & 1862 & 100 \\
\hline Fusion rate & $0 / 141$ & 0 & $0 / 81$ & 0 & $247 / 1668$ & 14.8 & $247 / 1809$ & 13.7 \\
\hline Complications & $11 / 141$ & 7.8 & $7 / 81$ & 8.6 & $64 / 1172$ & 5.5 & $75 / 1313$ & 5.7 \\
\hline Wound dehiscence & $2 / 141$ & 1.4 & $1 / 81$ & 1.2 & $6 / 1172$ & 0.5 & $8 / 1313$ & 0.6 \\
\hline Infection & $0 / 141$ & 0 & $0 / 81$ & 0 & 10/1172 & 0.9 & $10 / 1313$ & 0.8 \\
\hline Epidural hematoma & $1 / 141$ & 0.7 & $1 / 81$ & 1.2 & $3 / 1172$ & 0.3 & $4 / 1313$ & 0.3 \\
\hline Seroma & $1 / 141$ & 0.7 & $1 / 81$ & 1.2 & $2 / 1172$ & 0.2 & $3 / 1313$ & 0.2 \\
\hline Deep vein thrombosis & $1 / 141$ & 0.7 & $1 / 81$ & 1.2 & $3 / 1172$ & 0.3 & $4 / 1313$ & 0.3 \\
\hline Pulmonary embolism & 0/141 & 0 & $0 / 81$ & 0 & $1 / 1172$ & 0.1 & $1 / 1313$ & 0.1 \\
\hline CSF leak & $6 / 141$ & 4.3 & $3 / 81$ & 3.7 & $39 / 1172$ & 3.3 & $45 / 1313$ & 3.4 \\
\hline \multicolumn{9}{|l|}{ Postop course } \\
\hline Postop listhesis & $11 / 141$ & 7.8 & $8 / 81$ & 9.9 & $31 / 852$ & 3.6 & $42 / 993$ & 4.2 \\
\hline Delayed fusion rate & $9 / 141$ & 6.4 & $7 / 81$ & 8.6 & $24 / 1050$ & 2.3 & $33 / 1191$ & 2.8 \\
\hline Recurrent cyst & $8 / 141$ & 5.7 & $6 / 81$ & 7.4 & $27 / 1419$ & 1.9 & $35 / 1560$ & 2.2 \\
\hline Contralat cyst $\ddagger$ & $0 / 141$ & 0 & $0 / 81$ & 0 & $11 / 938$ & 1.2 & $11 / 1079$ & 1.0 \\
\hline Back pain $\ddagger$ & $27 / 141$ & 19.1 & $23 / 81$ & 28.4 & $131 / 594$ & 22.1 & $158 / 735$ & 21.5 \\
\hline
\end{tabular}

number of identified cysts has risen to $5.8 \%$ in the last decades. $^{21,24,68}$ The incidence in radiological studies may be misleading, because not all intraoperatively encountered cystic lesions are seen on preoperative imaging. ${ }^{69}$ Nevertheless, incidence calculations based on surgical findings still range from $0.5 \%$ to $2.2 \% .16,46,82$

Since the first description of a joint cyst as the cause of a nerve root compression by Vossschulte and Börger in $1950,{ }^{96} 123$ case series and 182 case reports of cysts of the spinal column have been published up to May 2016, according to our extensive literature search. Together with the present series, there are 3041 cysts in 2842 patients reported in the literature. The distribution of cyst locations is shown in Table 1. Overall, 234 studies report on surgical treatment, 25 report on injection and/or percutaneous cystrupture or aspiration techniques, 33 refer to radiological findings in the cystic lesions without mentioning any treatment, and 13 reports present conservative treatment, with 4 of those reports focusing on chiropractic techniques.

There are 6 series with more than 100 cases. ${ }^{4,15,53,60,85,100}$ However, although Scholz et al ${ }^{85}$ reported 148 patients with cysts of the spine, they focused on only 8 cases, and the remaining 140 were not further mentioned. Therefore, the present series in which 141 patients were completely reviewed is the third-largest series, and is by far the largest one with a follow-up of more than 4 years, with 81 patients in the long-term follow-up group (Supplemental Table 1). Furthermore, the mean follow-up period of these patients was 9.3 years. Only Weiner et al..$^{97}$ presented a series of 46 patients with a slightly longer mean follow-up-of 9.7 years.

Spinal cysts can be divided into true synovial cysts and pseudocysts. Synovial cysts contain a synovial or synovial-like lining, are filled with clear or xanthochromic fluid, and can contain granulation tissue as well as histiocytes and giant cells. ${ }^{28,101}$ Sometimes a communication between the synovial sheath or joint capsule can be seen in histopathological examination. ${ }^{101}$ Pseudocysts have a collagenous capsule without a mesothelial lining, are filled with myxoid material, and do not communicate with the joint. ${ }^{29,101}$ Pseudocysts may be classified into ganglion cysts, which are located in the periarticular fibrous tissues, and ligamentous cysts, which are located in the ligamentum flavum or in the posterior longitudinal ligament. $7,25,32,34,48$ The terms "synovial cysts" and "ganglion cysts" have been combined to designate juxtaarticular cysts or juxtafacet cysts. ${ }^{27,39,83}$ The term "juxtafacet cyst" was introduced by Kao et al. ${ }^{39}$ in 1974 , and encompasses all cysts located adjacent to the facet joints or cysts arising from or extending into the ligamentum flavum..$^{7,32,81}$ To combine juxtafacet cysts seems to be reasonable, because the distinction of synovial or ganglion cysts is of pathological interest only, and surgical treatment and prognosis seems to be identical. ${ }^{34,53,81}$ Furthermore, some authors suggest that the presence or absence of synovium in the cysts is an arbitrary distinction that represents end points on a histological continuum, and that synovial cysts may evolve into ganglion cysts and vice versa. ${ }^{36,87,101}$

The pathogenesis of synovial cysts is still a matter of discussion. One theory for the development of these cysts is the degeneration process and excessive joint mobility, which together with microtrauma and a defective joint capsule, lead to herniation of synovium..$^{34,101}$ Other theories assume cyst formation due to synovial fluid extrusion from the joint capsule, ${ }^{71}$ or lodged fragments of debris of the joint surface in preexisting bursal channels leading to 
TABLE 4. Long-term follow-up cohort and comparison of patients with and without delayed fusion in this subgroup

\begin{tabular}{|c|c|c|c|c|}
\hline \multirow[b]{2}{*}{ Variable } & \multicolumn{3}{|c|}{ Long-Term FU Cohort } & \multirow[b]{2}{*}{$\begin{array}{c}p \\
\text { Value }\end{array}$} \\
\hline & $\begin{array}{l}\text { Total, } \\
\mathrm{n}=81\end{array}$ & $\begin{array}{c}\text { w/o } \\
\text { Delayed } \\
\text { Fusion, } \\
n=74\end{array}$ & $\begin{array}{c}\text { w/ } \\
\text { Delayed } \\
\text { Fusion, } \\
n=7\end{array}$ & \\
\hline \multicolumn{5}{|l|}{ Patient characteristics } \\
\hline Mean age in yrs, \pm SD & $65 \pm 11$ & $64 \pm 12$ & $67 \pm 10$ & 0.6 \\
\hline Female & $67.9 \%$ & $67.6 \%$ & $71.3 \%$ & 1.0 \\
\hline \multicolumn{5}{|l|}{ Location \& radiological findings } \\
\hline $\mathrm{C} 7 / \mathrm{T} 1$ & $1.2 \%$ & $1.4 \%$ & $0 \%$ & \multirow{6}{*}{0.8} \\
\hline $\mathrm{L} 1 / 2$ & $2.5 \%$ & $2.7 \%$ & $0 \%$ & \\
\hline $\mathrm{L} 2 / 3$ & $2.5 \%$ & $2.7 \%$ & $0 \%$ & \\
\hline $\mathrm{L} 3 / 4$ & $19.8 \%$ & $18.9 \%$ & $28.6 \%$ & \\
\hline $\mathrm{L} 4 / 5$ & $58.0 \%$ & $56.8 \%$ & $71.4 \%$ & \\
\hline L5/S1 & $16.0 \%$ & $17.6 \%$ & $0 \%$ & \\
\hline Spondylolisthesis preop & $23.5 \%$ & $23.0 \%$ & $28.6 \%$ & 0.7 \\
\hline \multicolumn{5}{|l|}{ Symptoms } \\
\hline Mean duration in mos & 5.7 & 6.0 & 1.9 & 0.2 \\
\hline Radiculopathy & $90.1 \%$ & $90.5 \%$ & $85.7 \%$ & 0.5 \\
\hline Neck or back pain & $91.4 \%$ & $90.5 \%$ & $100 \%$ & 1.0 \\
\hline Sensory deficit & $46.9 \%$ & $48.6 \%$ & $28.6 \%$ & 0.4 \\
\hline Motor deficit & $35.8 \%$ & $35.1 \%$ & $42.9 \%$ & 0.7 \\
\hline Cauda equina syndrome* & $4.9 \%$ & $4.1 \%$ & $14.3 \%$ & 0.3 \\
\hline \multicolumn{5}{|l|}{ Surgical procedure } \\
\hline Interlaminary fenestration & $3.7 \%$ & $2.7 \%$ & $14.29 \%$ & \multirow{4}{*}{0.5} \\
\hline Partial hemilaminectomy & $74.1 \%$ & $74.3 \%$ & $71.4 \%$ & \\
\hline Hemilaminectomy & $19.8 \%$ & $20.3 \%$ & $14.3 \%$ & \\
\hline Laminectomy & $2.5 \%$ & $2.7 \%$ & $0 \%$ & \\
\hline No facet resection & $67.9 \%$ & $67.6 \%$ & $71.4 \%$ & \multirow{3}{*}{0.8} \\
\hline $1 / 3$ facet resection & $6.2 \%$ & $6.8 \%$ & $0 \%$ & \\
\hline $2 / 3$ facet resection & $25.9 \%$ & $25.7 \%$ & $28.6 \%$ & \\
\hline \multicolumn{5}{|l|}{ Long-term outcome† } \\
\hline Mean FU time in mos, \pm SD & $111 \pm 44$ & $110 \pm 44$ & $132 \pm 49$ & 0.2 \\
\hline No disability & $44.4 \%$ & $47.3 \%$ & $14.3 \%$ & \multirow{4}{*}{$<0.05$} \\
\hline Minimal disability & $33.3 \%$ & $32.4 \%$ & $42.9 \%$ & \\
\hline Moderate disability & $16.1 \%$ & $16.2 \%$ & $14.3 \%$ & \\
\hline Severe disability & $6.2 \%$ & $4.1 \%$ & $28.6 \%$ & \\
\hline Crippled & $0 \%$ & $0 \%$ & $0 \%$ & \\
\hline Bed bound & $0 \%$ & $0 \%$ & $0 \%$ & \\
\hline
\end{tabular}

Boldface type indicates statistical significance.

* With or without bowel and/or bladder dysfunction in patients with thoracic or lumbar cysts. There were 80 patients total with cauda equina syndrome, 73 of them without delayed fusion.

† Status assigned based on the ODI score.

cystic dilation. ${ }^{32}$ Common to all explanations for juxtafacet cyst development seems to be joint destabilization due to traumatic or-far more frequently-degenerative changes in the ligamentum flavum and the facet joints. ${ }^{47}$ Not surprisingly, facet joint degeneration and hypertrophy of the facets is present in most of the patients. ${ }^{11,24,27,34,36,73,81,93} \mathrm{In}-$ stability of the facets and spondylolisthesis is more often seen in patients with cysts than in those without cysts. ${ }^{21}$ There is a strong variation of spondylolisthesis incidence, and it has been reported in up to $82 \%$ of cases in the literature. ${ }^{42}$ The rate of spondylolisthesis in the segment with the cyst was $23 \%$ in the present series. The overall rate of spondylolisthesis in the literature is $31 \%$ of all cases in which this issue was mentioned. The spondylolisthesis rate in the present series may be lower due to lack of standardized diagnostic procedures. Flexion and extension radiographs were obtained only if listhesis was suspected due to specific symptoms or radiological findings. However, in concordance with the literature, most of the patients had only minor spondylolisthesis (Grade I) according to the Meyerding classification system. ${ }^{20,53,64,84,87,100}$

Trauma has been suspected to play a major role in cyst development. However, only 1 patient $(0.7 \%)$ in the present study had a trauma previous to admission, and only $7 \%$ of the cases reported in the literature in which trauma was mentioned had trauma previous to cyst diagnosis. Because degeneration is much more common in the elderly, trauma seems to play a bigger role in younger patients for cyst development not attributable to malformations. ${ }^{3}$

\section{Patient Characteristics}

The mean age of patients in this series was 65.2 years. The mean age of all 2707 patients with cystic lesions reported in the literature was 62.6 years. The youngest patient was an 8-year-old boy, the oldest was a 92-year-old woman, both with a retrodental cyst. ${ }^{37,95}$ The youngest patient with a juxtafacet cyst was 14 years old, ${ }^{30}$ and the oldest was 86 years old. ${ }^{6}$ Cysts in younger patients are often combined with malformations or trauma. However, 74\% of all patients are in the 6th decade of life, in line with our findings.

Most patients in the present study were female (64\%). However, this percentage is somewhat higher than the female rate in the literature, which was $56 \%$ (Table 2).

\section{Location of Cyst}

Supporting the degeneration theory, more than $90 \%$ of these cysts are found in the lumbar spine, posterolateral to the thecal sac, causing central or-more frequently-lateral recess stenosis..$^{23,24}$ By far, the most frequent spinal level with a cyst finding in the present series, in line with the existing literature, is the L4/5 level, followed by the adjacent levels (Table 1). The second most frequent region for cysts is the cervical spine. Even though only 1 patient in the present series had a cyst at the cervicothoracic junction, $6.6 \%$ of all reported cysts in the literature arise in the cervical region of the spine. The cervicothoracic junction $(\mathrm{C} 7 / \mathrm{T} 1)$ is the fourth most frequent level for cysts in the literature, demonstrating the high mechanical stress on the joints in this segment. Reports of cysts located in the thoracic region are very rare; to the best of our knowledge, only 50 cases have been reported in the literature. Especially at the upper thoracic spine, cysts have been found in only a few cases, emphasizing the significance of movement and physical stress in the development of cysts, because the thoracic spine is the most rigid part. No patient was treated in our institution for a thoracic cyst of the spine within the observed time period of this study. 
Some patients present with multiple cysts at the same or different levels. ${ }^{11,28,41,75}$ In concordance with the literature, bilateral cysts at the same level were found in 3 patients (2\%) in this survey (see references in Supplemental Table 1).

There was no difference between locations of the cysts in terms of side in the present study. In the literature there is no significant difference between left and right either; $49 \%$ are found on the left and $51 \%$ are on the right side.

As mentioned above, most cysts are found posterolateral to the thecal sac. ${ }^{23,24}$ However, juxtafacet cysts can arise anywhere adjacent to the facet joints, and cause intra- or extraforaminal nerve compression; ${ }^{24,40,43,64,92}$ even intradural cysts have been reported. ${ }^{9,89}$ Just as disc herniation can occur far lateral to the foramen, ${ }^{58}$ synovial cysts can cause far-lateral nerve impairment as well. ${ }^{56,74}$ Interestingly, in a radiological survey of patients with symptomatic lumbar cysts, Doyle and Merrilees ${ }^{21}$ observed 3 times more cysts posterior, and therefore outside the spinal canal, than anterior to the facet joint. Other reports found nearly the same number of cysts anterior and posterior to the facet. ${ }^{1}$

Cysts in the posterior ligament are rare and have been

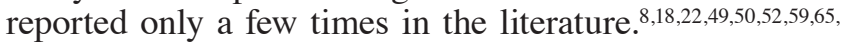
${ }^{70,94}$ They have only been found in the lumbar spine, and patients are significantly younger than those with juxtafacet cysts (mean 35 years vs 63 years; $p<0.001$ ).

\section{Symptoms and Signs}

Symptoms and signs depend to a large extent on the size and location of the cyst,,$^{24,41,75}$ and are most frequently a result of nerve root or spinal cord compression. ${ }^{24,27,93}$ Even though it is very rare, cranial nerve involvement has been described ${ }^{66}$ In the literature and according to our findings, pain is the most frequent symptom in patients with cysts of the spine. Nearly all patients had radicular pain at presentation in the present series; the second most frequent symptom was back pain, followed by sensory and motor deficits. Because the only patient with a juxtafacet cyst not located at the lumbar part of the spine presented with radiculopathy only, myelopathy was not present in any patient in this series. However, nearly half of the patients in the literature who had cysts of the cervical or thoracic spine presented with symptoms of myelopathy ${ }^{46}$ (Table 2).

In line with the literature, neurogenic claudication was the next most frequent symptom in the present series and was found up to twice as often in patients with bilateral cysts. ${ }^{81}$ In $20 \%$ of our cases the symptoms were bilateral; in the literature, $26 \%$ of patients had bilateral symptoms. Cauda equina syndrome with or without bowel and/or bladder dysfunction is relatively rare; it was present in $4 \%$ of patients with thoracic or lumbar cysts in the literature and in $5 \%$ of patients in the present series.

The symptom duration in the present series ranged from 2 weeks to 48 months; only 1 patient presented with an exceptional 15 years of symptom duration. The mean symptom duration in our patients was 6 months, and the mean duration of symptoms in patients reported in the literature was 10 months $(\mathrm{p}<0.001)$. This significantly longer symptom duration in patients reported in the literature may be explained by much longer symptom duration until diagnosis in series published before 1990, due to inferior diagnostic techniques at that time. ${ }^{20}$ The mean symptom duration in reports dated before 1990 was 37 months, compared with a mean symptom duration of 9 months in more recent reports $(\mathrm{p}<0.001)$.

The longest symptom duration reported in the literature is 10 years, but some authors reported acute onset of symptoms within days or even 1 day. 17,26,35,50,62,90,91,98,99 Acute hemorrhage into the cyst is believed by many authors to lead to this acute or aggravated symptomatic compression of neural structures, because hemorrhage has been found in many cysts with short symptom duration. ${ }^{19,29,35,38,48,71,77}$ However, intracystic hemorrhage is not necessarily correlated with acute onset of symptoms..$^{53,64}$

\section{Treatment Options}

Conservative treatment options such as bed rest, analgesics, lumbar corsets, physical therapy, and transcutaneous electrical stimulation are generally not effective, and further treatment is required. However, conservative options have been successful in some cases, and even spontaneous remission of the cyst has been described. ${ }^{33,36,51,55,60,61,63,67}$ Steroid injection into the facet joint with or without cyst aspiration showed similar results, with symptom relief only in exceptional cases, often requiring several procedures. ${ }^{83}$ However, larger case series revealed only short-term relief of symptoms and a generally poor outcome. ${ }^{13,73,80}$ In a series reported by Parlier-Cuau et al. ${ }^{73}$ more than $64 \%$ of patients had fair or poor results, and 50\% needed surgery within 6 months due to persistent or rapid symptom recurrence, with good results after operation. If rupture of the cyst via fluoroscopic percutaneous corticosteroid injection is targeted and accomplished, success rates can be increased. ${ }^{2,4,15,45,60,72}$ Amoretti et al. ${ }^{4}$ recorded durable results in $75 \%$ of 120 patients after 1 year. Martha et al ${ }^{60}$ reported a cyst rupture rate of $81 \%$ in 101 patients, but $54 \%$ required surgical intervention within 1 year.

Outcomes of the conservative treatment strategies mentioned above vary among the studies, and improvement is mostly temporary, because percutaneous techniques cannot address the stenosis resulting from hypertrophy of the ligamentum flavum and the facet that usually accompanies the cyst. ${ }^{20,75}$ Nevertheless, noninvasive treatment is an option in cases of severe illness or other contraindications for surgery. ${ }^{45,97}$

As shown in the present series, excision of the cyst and decompression of neural structures is effective; can be performed with low risk; and leads to immediate, dramatic pain relief and improvement of the symptoms in the majority of cases. ${ }^{12,24,28,34,53,75,81,87,101}$ Various techniques for cyst resection have been described. In the present series, partial or complete hemilaminectomy followed by interlaminary fenestration were the most frequent approaches, in accordance with the literature. ${ }^{44}$ The main problem associated with cyst resection is the frequent adherence to the dura, ${ }^{34}$ because incautious resection of the cyst can lead to dural leakage in these cases.$^{83}$ Therefore, a clean cleavage between the cyst and the dura should be carefully developed; ${ }^{5}$ however, due to the relatively small number of recurrent cysts, dural or neural structures should not be put at risk to achieve total resection, and parts of the 
cyst wall should be left behind if strongly adherent to the dura..$^{23,27,81,83}$ Despite the dural adherence, total cyst resection rates ranging from $45 \%$ to $100 \%$ are reported in the literature. . $23,53,64$ In the current series, dural adherence was present in $72 \%$ of cases; nevertheless, total removal of the cysts was achieved in $94 \%$.

Some authors have stated that most often the facet needs to be partially removed to achieve total removal of the cyst. ${ }^{5,27}$ However, to maintain stability, smaller and less traumatic facet-sparing approaches are favored in the literature. $^{71,79,84,86,88,93,102}$ Partial resection of the medial aspects of the facet was necessary in only one-third of cases in the present series.

\section{To Fuse or Not to Fuse}

As mentioned by Gupta and Lutz, ${ }^{32}$ fusion is a topic of dispute when it comes to the treatment of spinal synovial cysts, and it seems to be more a matter of philosophy about the extent of spinal surgery. Obviously, fusion is recommended in cases of high-grade spondylolisthesis, and should be considered if the patient's spine is deemed unstable or at high risk of becoming unstable following facetectomy. ${ }^{81}$ Furthermore, fusion without cyst evacuation was proven to be effective in cases of cysts arising from the $\mathrm{C} 1 / 2$ joint, ${ }^{76}$ which is clearly an exceptional location. However, symptom relief, long-term outcome, and the rate of cyst recurrence with or without fusion are not different in the literature, ${ }^{14,42,99}$ despite an increase of mechanical back pain in the nonfusion group reported by $\mathrm{Xu}$ et al. ${ }^{100}$ Information concerning fusion was reported for 1668 patients in the literature, and fusion was performed in $15 \%$ during the cyst resection procedure (Supplemental Table 1). The recurrence rate in studies and reports in which $50 \%$ or more of the observed cases were initially treated with fusion was nearly equal to that in studies or reports in which less than $50 \%$ or no case was fused $(2.5 \%$ vs $2.2 \%, \mathrm{p}=0.8)$. However, recurrent cysts do not usually occur in fused cases, and back pain problems seem to be better addressed with fusion. ${ }^{44}$ Instrumented fusion is accompanied by a longer hospital stay, a greater amount of intraoperative blood loss, and a higher number of perioperative complications. ${ }^{44,100}$

In the present series, none of the 141 patients underwent fusion during the initial operation, the overall recurrence rate was $5.7 \%$, and the overall rate of delayed fusion was $6.4 \%$. However, recurrence and delayed fusion rates in the 81 patients with a structured long-term follow-up of 9.3 years seem to be more reliable (Table 3 ).

Cyst recurrence was observed in $7.4 \%$ of cases with long-term follow-up. This higher number of recurrent cysts in the present series can be explained by the exceptionally long follow-up period, because only 2 cysts recurred within the 1st year after operation and 4 cysts recurred more than 3 years after the operation. Delayed fusion was necessary in $8.6 \%$ of patients in the long-term follow-up group. Again, most of these cases required fusion many years after the initial procedure. Furthermore, the followup period tended to be longer in patients with delayed fusion than in patients without. Twenty-four of 1050 patients in the literature for whom information about delayed fusion or about the operation not being performed was given underwent fusion within the follow-up period (2.3\%). As shown in Table 4, reports with more than a 4-year followup had a higher delayed fusion rate than reports with a shorter follow-up. Therefore, the long follow-up of the present series may explain the somewhat higher delayed fusion rate in our study compared with the literature. However, patients undergoing fusion within the follow-up period reported that their disabilities occur significantly more often and at a more severe level at the time of follow-up compared with patients without fusion. It remains a matter of speculation whether a fusion at the time of cyst resection might have prevented disabilities in these patients. The fact that the reported disabilities are still present after the fusion procedure may indicate a progressive degenerative process in these patients in addition to the initial cystinducing pathology.

Results of the present study, in which there were a low number of recurrent cysts and delayed fusions in long-term follow-up, together with findings in the literature, encourage our proposed method of treatment. The presence of degenerative cysts of the spine should not necessarily require stabilization procedures when bone- and facet-sparing approaches are used ${ }^{20,48}$ and when pre- and intraoperative findings are carefully examined to determine the appropriateness of concomitant fusion. ${ }^{53}$

\section{Postoperative Outcome}

Outcome after surgical treatment seems not to be correlated with the age, height, or weight of the patients. ${ }^{42}$ Trummer et al..$^{93}$ found no difference in outcomes between the hemilaminectomy or flavectomy approaches. Overall, most patients achieve excellent or good results with surgical intervention. 5,11,27,36,44,53,71,83 Concerning the direct postoperative outcome, we found cure of leg pain in $88 \%$ of the 141 patients, $86 \%$ no longer had sensory deficits, and $86 \%$ showed restored or markedly improved muscle function. These findings are consistent with the literature, and the majority of patients report relief of symptoms and favorable, good, or excellent outcomes in short-term follow-up (Table 4). ${ }^{53,64}$

After a mean long-term follow-up of 9.3 years, $80 \%$ of patients in this series reported an excellent outcome, $14 \%$ reported a good outcome, and $6 \%$ reported a fair or poor outcome. Excellent and good outcome rates in the literature range from $65 \%$ to $100 \%, 5,11,27,36,44,53,71,83$ and a good to excellent outcome can be achieved regardless of lumbar, thoracic, or cervical location of the cyst. . $^{31,34,53}$

Information concerning excellent outcomes with complete relief of symptoms after surgical treatment was given for 1022 patients in the literature, and excellent outcome rates ranged from $25 \%$ to $100 \%$ (Supplemental Table 1). Overall, 68\% had excellent outcomes, while $23 \%$ had good, $6 \%$ had fair, and $3 \%$ had poor outcomes. With the assumption that cases with good or excellent outcomes are more likely to be reported, an excellent or good outcome was reported in single case reports or reports with fewer than 10 patients (92 reports with 187 patients) in $83 \%$ and $14 \%$ of reports, respectively. However, case series with more than 20 patients (17 reports with 675 patients) had a rate of $64 \%$ excellent and $24 \%$ good outcome, which was only somewhat lower compared with the overall rate. Fu- 
sion, too, is not associated with better outcome; conversely, nonfused cases are not associated with a higher rate of unfavorable outcome in the literature. In 14 series with 50\%-100\% fusion rates, including 102 patients, an excellent outcome was achieved in $70 \%$ and a good outcome in $20 \%$. In 91 series including 611 patients without concomitant fusion, an excellent outcome was achieved in $71 \%$ and a good outcome in $19 \%$. Interestingly, outcome rates in the present series were worse in patients in whom delayed fusion was necessary, as mentioned above.

Patients with lumbar cysts had significantly better outcome rates than those with thoracic or cervical cysts after surgical treatment. That is, $91 \%$ of patients with lumbar cysts had excellent and good outcomes, compared with patients who had thoracic or cervical cysts; in both of those groups, the rate of good or excellent outcomes was only $84 \%(\mathrm{p}<0.001)$.

As we have shown in the present series, high rates of excellent or good outcomes are preserved even in cohorts with long-term follow-up. Studies with follow-up periods of less than 4 years had a good or excellent outcome rate of $91 \%$ (833 patients in 115 reports). Even in studies with follow-up periods of more than 4 years, good or excellent outcomes were reported in $95 \%$ (189 patients in 7 reports). Our results were equal to those reported in the only other study with a follow-up period of more than 9 years, in which Weiner et al. reported symptom relief in $88 \%$ of their patients. ${ }^{97}$

\section{Limitations of the Study}

This study has several limitations. Because of the retrospective design and the potential for bias, the typical restrictions apply, such as the lack of data (i.e., information not documented initially in the medical records). Moreover, the use of a telephone interview to conduct the long-term follow-up allows a lack of objectivity, and selection bias cannot be eliminated. However, we were able to achieve a reasonable follow-up rate with structured, questionnaire-based information about current symptoms and further surgical procedures, with a follow-up period of more than 9 years. Together with the high number of patients, this might counteract the disadvantages.

\section{Conclusions}

We present the largest series of patients with a long-term follow-up of more than 9 years after resection of juxtafacet cysts. Degenerative cysts of the spine are generally rare, but treatment can be challenging due to frequent dural adherence. Surgical treatment with resection of the cyst provides a favorable outcome. An excellent or good outcome can be achieved in the vast majority of cases, and persists after a long-term follow-up period. Complication rates are low, despite an increased risk for dural injury. Therefore, the approach should allow complete visualization of the cyst in order to prepare a clean cleavage between the lesion and the dura. Total resection can be performed in most cases, and recurrence rates are low. With facet-sparing techniques, stability of the surgically treated segment can be preserved, and resection of juxtafacet cysts does not necessarily require segmental fusion.

\section{References}

1. Alicioglu B, Sut N: Synovial cysts of the lumbar facet joints: a retrospective magnetic resonance imaging study investigating their relation with degenerative spondylolisthesis. Prague Med Rep 110:301-309, 2009

2. Allen TL, Tatli Y, Lutz GE: Fluoroscopic percutaneous lumbar zygapophyseal joint cyst rupture: a clinical outcome study. Spine J 9:387-395, 2009

3. Alyas F, Turner M, Connell D: MRI findings in the lumbar spines of asymptomatic, adolescent, elite tennis players. Br J Sports Med 41:836-841, 2007

4. Amoretti N, Huwart L, Foti P, Boileau P, Amoretti ME, Pellegrin A, et al: Symptomatic lumbar facet joint cysts treated by CT-guided intracystic and intra-articular steroid injections. Eur Radiol 22:2836-2840, 2012

5. Artico M, Cervoni L, Carloia S, Stevanato G, Mastantuono M, Nucci F: Synovial cysts: clinical and neuroradiological aspects. Acta Neurochir (Wien) 139:176-181, 1997

6. Asamoto S, Jimbo H, Fukui Y, Doi H, Sakagawa H, Ida M, et al: Cyst of the ligamentum flavum-case report. Neurol Med Chir (Tokyo) 45:653-656, 2005

7. Ayberk G, Ozveren F, Gök B, Yazgan A, Tosun H, Seçkin $\mathrm{Z}$, et al: Lumbar synovial cysts: experience with nine cases. Neurol Med Chir (Tokyo) 48:298-303, 2008

8. Baba H, Furusawa N, Maezawa Y, Uchida K, Kokubo Y, Imura S, et al: Ganglion cyst of the posterior longitudinal ligament causing lumbar radiculopathy: case report. Spinal Cord 35:632-635, 1997

9. Bae JS, Lee SH, Kim JS, Myung SH, Paeng SS: Intradural invasion of lumbar synovial cyst. Case report. Neurol Med Chir (Tokyo) 52:234-237, 2012

10. Baker WM: On the formation of synovial cysts in the leg in connection with disease of the knee-joint. 1877. Clin Orthop Relat Res (299):2-10, 1994

11. Banning CS, Thorell WE, Leibrock LG: Patient outcome after resection of lumbar juxtafacet cysts. Spine (Phila Pa 1976) 26:969-972, 2001

12. Bisson EF, Sauri-Barraza JC, Niazi T, Schmidt MH: Synovial cysts of the cervicothoracic junction causing myelopathy: report of 3 cases and review of the literature. Neurosurg Focus 35(1):E3, 2013

13. Bjorkengren AG, Kurz LT, Resnick D, Sartoris DJ, Garfin SR: Symptomatic intraspinal synovial cysts: opacification and treatment by percutaneous injection. AJR Am J Roentgenol 149:105-107, 1987

14. Bydon M, Lin JA, de la Garza-Ramos R, Sciubba DM, Wolinsky JP, Witham TF, et al: The role of spinal fusion in the treatment of cervical synovial cysts: a series of 17 cases and meta-analysis. J Neurosurg Spine 21:919-928, 2014

15. Cambron SC, McIntyre JJ, Guerin SJ, Li Z, Pastel DA: Lumbar facet joint synovial cysts: does T2 signal intensity predict outcomes after percutaneous rupture? AJNR Am J Neuroradiol 34:1661-1664, 2013

16. Charest DR, Kenny BG: Radicular pain caused by synovial cyst: an underdiagnosed entity in the elderly? J Neurosurg 92 (1 Suppl):57-60, 2000

17. Cheng WY, Shen CC, Wen MC: Ganglion cyst of the cervical spine presenting with Brown-Sequard syndrome. J Clin Neurosci 13:1041-1045, 2006

18. Cho SM, Rhee WT, Lee SY, Lee SB: Ganglion cyst of the posterior longitudinal ligament causing lumbar radiculopathy. J Korean Neurosurg Soc 47:298-301, 2010

19. Cicuendez M, Alen JF, Ramos A, Lobato RD, Lagares A: Spontaneous hemorrhage into a lumbar synovial cyst. Eur Spine J 19 (Suppl 2):S190-S192, 2010

20. Deinsberger R, Kinn E, Ungersböck K: Microsurgical treatment of juxta facet cysts of the lumbar spine. J Spinal Disord Tech 19:155-160, 2006

21. Doyle AJ, Merrilees M: Synovial cysts of the lumbar facet 
joints in a symptomatic population: prevalence on magnetic resonance imaging. Spine (Phila Pa 1976) 29:874-878, 2004

22. Eggert HR, Agnoli AL, Mennel HD: Lumbar intraspinal ganglion cyst: case reports. Acta Neurochir (Wien) 59:263-266, 1981

23. Epstein NE: Lumbar synovial cysts: a review of diagnosis, surgical management, and outcome assessment. J Spinal Disord Tech 17:321-325, 2004

24. Eyster EF, Scott WR: Lumbar synovial cysts: report of eleven cases. Neurosurgery 24:112-115, 1989

25. Finkelstein SD, Sayegh R, Watson P, Knuckey N: Juxtafacet cysts. Report of two cases and review of clinicopathologic features. Spine (Phila Pa 1976) 18:779-782, 1993

26. Freedman BA, Bui TL, Yoon ST: Diagnostic challenge: bilateral infected lumbar facet cysts - a rare cause of acute lumbar spinal stenosis and back pain. J Orthop Surg 5:14, 2010

27. Freidberg SR, Fellows T, Thomas CB, Mancall AC: Experience with symptomatic spinal epidural cysts. Neurosurgery 34:989-993, 1994

28. Ganau M, Ennas F, Bellisano G, Ganau L, Ambu R, Faa $\mathrm{G}$, et al: Synovial cysts of the lumbar spine-pathological considerations and surgical strategy. Neurol Med Chir (Tokyo) 53:95-102, 2013

29. Gazzeri R, Canova A, Fiore C, Galarza M, Neroni M, Giordano M: Acute hemorrhagic cyst of the ligamentum flavum. J Spinal Disord Tech 20:536-538, 2007

30. Gelabert-González M, Prieto-González A, María SantinAmo J, Serramito-García R, García-Allut A: Lumbar synovial cyst in an adolescent: case report. Childs Nerv Syst 25:719-721, 2009

31. Graham E, Lenke LG, Hannallah D, Lauryssen C: Myelopathy induced by a thoracic intraspinal synovial cyst: case report and review of the literature. Spine (Phila Pa 1976) 26:E392-E394, 2001

32. Gupta A, Lutz GE: Synovial cysts: to fuse or not to fuse? Spine J 10:817-819, 2010

33. Houten JK, Sanderson SP, Cooper PR: Spontaneous regression of symptomatic lumbar synovial cysts. Report of three cases. J Neurosurg 99 (2 Suppl):235-238, 2003

34. Howington JU, Connolly ES, Voorhies RM: Intraspinal synovial cysts: 10 -year experience at the Ochsner Clinic. J Neurosurg 91 (2 Suppl):193-199, 1999

35. Howling SJ, Kessel D: Case report: acute radiculopathy due to a haemorrhagic lumbar synovial cyst. Clin Radiol 52:73-74, 1997

36. Hsu KY, Zucherman JF, Shea WJ, Jeffrey RA: Lumbar intraspinal synovial and ganglion cysts (facet cysts). Tenyear experience in evaluation and treatment. Spine (Phila Pa 1976) 20:80-89, 1995

37. Ito T, Hayashi M, Ogino T: Retrodental synovial cyst which disappeared after posterior C1-C2 fusion: A case report. J Orthop Surg (Hong Kong) 8:83-87, 2000

38. Kaneko K, Inoue Y: Haemorrhagic lumbar synovial cyst. A cause of acute radiculopathy. J Bone Joint Surg Br 82:583-584, 2000

39. Kao CC, Winkler SS, Turner JH: Synovial cyst of spinal facet. Case report. J Neurosurg 41:372-376, 1974

40. Kemaloğlu S, Nas K, Gür A, Bukte Y, Ceviz A, Ozkan U: Synovial cyst at the intervertebral foramina causing lumbar radiculopathy. Spinal Cord 39:399-401, 2001

41. Khan AM, Girardi F: Spinal lumbar synovial cysts. Diagnosis and management challenge. Eur Spine J 15:1176-1182, 2006

42. Khan AM, Synnot K, Cammisa FP, Girardi FP: Lumbar synovial cysts of the spine: an evaluation of surgical outcome. J Spinal Disord Tech 18:127-131, 2005

43. Kim JU, Lee SH, Lee DY: Extraforaminal lumbar synovial cyst causing sudden foot drop: case report. Neurol Med Chir (Tokyo) 48:578-581, 2008

44. Knafo S, Page P, Pallud J, Roux FX, Abi-Lahoud G: Surgical management of spinal synovial cysts. J Spinal Disord Tech 28:277-217, 2012

45. Kozar S, Jeromel M: Minimally invasive CT guided treatment of intraspinal synovial cyst. Radiol Oncol 48:35-39, 2014

46. Krauss WE, Atkinson JL, Miller GM: Juxtafacet cysts of the cervical spine. Neurosurgery 43:1363-1368, 1998

47. Kusakabe T, Kasama F, Aizawa T, Sato T, Kokubun S: Facet cyst in the lumbar spine: radiological and histopathological findings and possible pathogenesis. J Neurosurg Spine 5:398-403, 2006

48. Landi A, Marotta N, Tarantino R, Ruggeri AG, Cappelletti M, Ramieri A, et al: Microsurgical excision without fusion as a safe option for resection of synovial cyst of the lumbar spine: long-term follow-up in mono-institutional experience. Neurosurg Rev 35:245-253, 2012

49. Le Breton C, Garreau de Luobresse C, Awky J, Khalil A, Sibony M, Judet T, et al: L5 radicular pain related to a cystic lesion of the posterior longitudinal ligament. Eur Radiol 10:1812-1814, 2000

50. Lee J, Wisneski RJ, Lutz GE: A ganglion cyst causing lumbar radiculopathy in a baseball pitcher: a case report. Arch Phys Med Rehabil 81:837-839, 2000

51. Lemish W, Apsimon T, Chakera T: Lumbar intraspinal synovial cysts. Recognition and CT diagnosis. Spine (Phila Pa 1976) 14:1378-1383, 1989

52. Lin RM, Wey KL, Tzeng CC: Gas-containing "ganglion" cyst of lumbar posterior longitudinal ligament at L3. Case report. Spine (Phila Pa 1976) 18:2528-2532, 1993

53. Lyons MK, Atkinson JL, Wharen RE, Deen HG, Zimmerman RS, Lemens SM: Surgical evaluation and management of lumbar synovial cysts: the Mayo Clinic experience. J Neurosurg 93 (1 Suppl):53-57, 2000

54. Macnab I: Negative disc exploration. An analysis of the causes of nerve-root involvement in sixty-eight patients. J Bone Joint Surg Am 53:891-903, 1971

55. Maezawa Y, Baba H, Uchida K, Furusawa N, Kubota C, Yoshizawa K: Spontaneous remission of a solitary intraspinal synovial cyst of the lumbar spine. Eur Spine J 9:85-87, 2000

56. Manabe M, Doita M, Yoshikawa M, Okamoto K, Sha N, Kurosaka M: Far lateral extraforaminal facet cyst causing L5 radiculopathy. J Spinal Disord Tech 19:447-450, 2006

57. Mannion AF, Junge A, Fairbank JCT, Dvorak J, Grob D: Development of a German version of the Oswestry Disability Index. Part 1: cross-cultural adaptation, reliability, and validity. Eur Spine J 15:55-65, 2006

58. Marquardt G, Bruder M, Theuss S, Setzer M, Seifert V: Ultra-long-term outcome of surgically treated far-lateral, extraforaminal lumbar disc herniations: a single-center series. Eur Spine J 21:660-665, 2012

59. Marshman LAG, Benjamin JC, David KM, King A, Chawda SJ: "Disc cysts" and "posterior longitudinal ligament ganglion cysts": synonymous entities? Report of three cases and literature review. Neurosurgery 57:E818, 2005

60. Martha JF, Swaim B, Wang DA, Kim DH, Hill J, Bode R, et al: Outcome of percutaneous rupture of lumbar synovial cysts: a case series of 101 patients. Spine J 9:899-904, 2009

61. Mattei TA, Goulart CR, McCall TD: Pathophysiology of regression of synovial cysts of the lumbar spine: the 'antiinflammatory hypothesis'. Med Hypotheses 79:813-818, 2012

62. McGuigan C, Stevens J, Gabriel CM: A synovial cyst in the cervical spine causing acute spinal cord compression. Neurology 65:1293, 2005 
63. Mercader J, Muñoz Gomez J, Cardenal C: Intraspinal synovial cyst: diagnosis by CT. Follow-up and spontaneous remission. Neuroradiology 27:346-348, 1985

64. Métellus P, Fuentes S, Adetchessi T, Levrier O, FloresParra I, Talianu D, et al: Retrospective study of 77 patients harbouring lumbar synovial cysts: functional and neurological outcome. Acta Neurochir (Wien) 148:47-54, 2006

65. Mizutamari M, Sei A, Fujimoto T, Taniwaki T, Mizuta H: L5 radiculopathy caused by a ganglion cyst of the posterior longitudinal ligament in a teenager. Spine J 9:e11-e14, 2009

66. Mujic A, Hunn A, Liddell J, Taylor B, Havlat M, Beasley T: Isolated unilateral hypoglossal nerve paralysis caused by an atlanto-occipital joint synovial cyst. J Clin Neurosci 10:492-495, 2003

67. Ngo T, Decina P, Hsu W: Spontaneous resolution of symptoms associated with a facet synovial cyst in an adult female - a case report. J Can Chiropr Assoc 57:87-92, 2013

68. Niggemann P, Kuchta J, Hoeffer J, Grosskurth D, Beyer HK, Delank KS: Juxtafacet cysts of the lumbar spine: a positional MRI study. Skeletal Radiol 41:313-320, 2012

69. Oertel MF, Ryang Y, Ince A, Gilsbach JM, Rohde V: Microsurgical therapy of symptomatic lumbar juxta facet cysts. Minim Invasive Neurosurg 46:349-353, 2003

70. Ogawa Y, Kumano K, Hirabayashi S, Aota Y: A ganglion cyst in the lumbar spinal canal. A case report. Spine (Phila Pa 1976) 17: 1429-1431, 1992

71. Onofrio BM, Mih AD: Synovial cysts of the spine. Neurosurgery 22:642-647, 1988

72. Ortiz AO, Tekchandani L: Improved outcomes with direct percutaneous CT guided lumbar synovial cyst treatment: advanced approaches and techniques. J Neurointerv Surg 6:790-794, 2014

73. Parlier-Cuau C, Wybier M, Nizard R, Champsaur P, Le Hir P, Laredo JD: Symptomatic lumbar facet joint synovial cysts: clinical assessment of facet joint steroid injection after 1 and 6 months and long-term follow-up in 30 patients. Radiology 210:509-513, 1999

74. Phuong LK, Atkinson JLD, Thielen KR: Far lateral extraforaminal lumbar synovial cyst: report of two cases. Neurosurgery 51:505-508, 2002

75. Pirotte B, Gabrovsky N, Massager N, Levivier M, David P, Brotchi J: Synovial cysts of the lumbar spine: surgery-related results and outcome. J Neurosurg 99 (1 Suppl):14-19, 2003

76. Puffer RC, Van Gompel JJ, Morris JM, Krauss WE: Resolution of cystic deterioration of the C1-2 articulation with posterior fusion: treatment implications for asymptomatic patients. World Neurosurg 79:773-778, 2013

77. Ramieri A, Domenicucci M, Seferi A, Paolini S, Petrozza V, Delfini R: Lumbar hemorrhagic synovial cysts: diagnosis, pathogenesis, and treatment. Report of 3 cases. Surg Neurol 65:385-390, 2006

78. Reddy P, Satyanarayana S, Nanda A: Synovial cyst of lumbar spine presenting as disc disease: a case report and review of literature. J La State Med Soc 152:563-566, 2000

79. Rhee J, Anaizi AN, Sandhu FA, Voyadzis J-M: Minimally invasive resection of lumbar synovial cysts from a contralateral approach. J Neurosurg Spine 17:453-458, 2012

80. Sabers SR, Ross SR, Grogg BE, Lauder TD: Procedurebased nonsurgical management of lumbar zygapophyseal joint cyst-induced radicular pain. Arch Phys Med Rehabil 86: 1767-1771, 2005

81. Sabo RA, Tracy PT, Weinger JM: A series of 60 juxtafacet cysts: clinical presentation, the role of spinal instability, and treatment. J Neurosurg 85:560-565, 1996

82. Sachdev VP, Savitz MH, Hindi AI, Goldstein HB: Synovial cysts of the lumbar facet joint. Mt Sinai J Med 58:125128,1991

83. Salmon B, Martin D, Lenelle J, Stevenaert A: Juxtafacet cyst of the lumbar spine. Clinical, radiological and therapeutic aspects in 28 cases. Acta Neurochir (Wien) 143:129134, 2001

84. Sandhu FA, Santiago P, Fessler RG, Palmer S: Minimally invasive surgical treatment of lumbar synovial cysts. Neurosurgery 54:107-112, 2004

85. Scholz C, Hubbe U, Kogias E, Klingler JH: Incomplete resection of lumbar synovial cysts - evaluating the risk of recurrence. Clin Neurol Neurosurg 136:29-32, 2015

86. Sehati N, Khoo LT, Holly LT: Treatment of lumbar synovial cysts using minimally invasive surgical techniques. Neurosurg Focus 20(3):E2, 2006

87. Shah RV, Lutz GE: Lumbar intraspinal synovial cysts: conservative management and review of the world's literature. Spine J 3:479-488, 2003

88. Sukkarieh HG, Hitchon PW, Awe O, Noeller J: Minimally invasive resection of lumbar intraspinal synovial cysts via a contralateral approach: review of 13 cases. J Neurosurg Spine 23:444-450, 2015

89. Tai PA, Li TC: Lumbar intradural ganglion cyst. World Neurosurg 88:691.e1-691.e4, 2016

90. Tatter SB, Cosgrove GR: Hemorrhage into a lumbar synovial cyst causing an acute cauda equina syndrome. Case report. J Neurosurg 81:449-452, 1994

91. Tobback IG, Parizel PM, Milants W, de Moor J, De Schepper AM: Gas-filled intraspinal synovial cyst. RoFo Fortschr Geb Rontgenstr Nuklearmed 156:300-301, 1992

92. Torres Campa-Santamarina J, Towne S, Alimi M, NavarroRamirez R, Härtl R: Minimally invasive approach for extraforaminal synovial cyst L5-S1. Cureus 7:e362, 2015

93. Trummer M, Flaschka G, Tillich M, Homann CN, Unger F, Eustacchio S: Diagnosis and surgical management of intraspinal synovial cysts: report of 19 cases. J Neurol Neurosurg Psychiatry 70:74-77, 2001

94. Vasani SS, Demetriades AK, Joshi SM, Yeh J, Ellamushi $\mathrm{H}$ : Traumatic intraspinal extradural ganglion cyst in a teenager: case report and review of the literature. Clin Neurol Neurosurg 109:88-91, 2007

95. Velán O, Rabadán A, Paganini L, Langhi L: Atlantoaxial joint synovial cyst: diagnosis and percutaneous treatment. Cardiovasc Intervent Radiol 31:1219-1221, 2008

96. Vossschulte K, Börger G: Anatomische und funktionelle Untersuchungen über den Bandscheibenprolaps. Langenbecks Arch klin Chir 265:329-355, 1950

97. Weiner BK, Torretti J, Stauff M: Microdecompression for lumbar synovial cysts: an independent assessment of long term outcomes. J Orthop Surg 2:5, 2007

98. Weng C, Wang LM, Wang WD, Tan HY: Bipartite atlas with os odontoideum and synovial cyst: case report and review literature. Spine (Phila Pa 1976) 35:E568-E575, 2010

99. Wills JH, Wiesel S, Abram SE, Rupp FW: Synovial cysts and the lithotomy position causing cauda equina syndrome. Reg Anesth Pain Med 29:234-236, 2004

100. Xu R, McGirt MJ, Parker SL, Bydon M, Olivi A, Wolinsky JP, et al: Factors associated with recurrent back pain and cyst recurrence after surgical resection of one hundred ninety-five spinal synovial cysts: analysis of one hundred sixty-seven consecutive cases. Spine (Phila Pa 1976) 35:1044-1053, 2010

101. Yarde WL, Arnold PM, Kepes JJ, O’Boynick PL, Wilkinson SB, Batnitzky S: Synovial cysts of the lumbar spine: diagnosis, surgical management, and pathogenesis. Report of eight cases. Surg Neurol 43:459-465, 1995

102. Zhenbo Z, Huanting L, Jin W, Haifeng G, Yuan F, Ming L: 
Hemilaminoplasty for the treatment of lumbar intraspinal synovial cysts (LISCs) and literature review. Eur Spine J 25:3393-3402, 2016

\section{Disclosures}

The authors report no conflict of interest concerning the materials or methods used in this study or the findings specified in this paper.

\section{Author Contributions}

Conception and design: Bruder, Marquardt. Acquisition of data: Bruder, Cattani, Droste. Analysis and interpretation of data: Bruder, Droste. Drafting the article: Bruder. Critically revising the article: Cattani, Gessler, Setzer, Seifert, Marquardt. Reviewed submitted version of manuscript: Gessler, Marquardt. Approved the final version of the manuscript on behalf of all authors: Brud- er. Statistical analysis: Bruder. Administrative/technical/material support: Seifert. Study supervision: Marquardt.

\section{Supplemental Information}

Previous Presentations

Portions of this work were presented in a lecture at the 67th Annual Meeting of the German Society of Neurosurgery (DGNC) together with the first Joint Meeting with the Korean Neurosurgical Society (KNS), held in Frankfurt, Germany, on June 16, 2016.

Online-Only Content

Supplemental material is available with the online version of the article.

Supplemental Table 1. https://thejns.org/doi/suppl/10.3171/ 2016.12.SPINE16756.

\section{Correspondence}

Markus Bruder, Department of Neurosurgery, Goethe University, Frankfurt 60528, Germany. email: markus.bruder@kgu.de. 